\title{
Factors affecting independent participants of Indonesia's National Health Insurance in paying premium compliance: a qualitative study
}

Deni Kurniadi Sunjaya ( $\nabla$ dk_sunjaya@yahoo.co.id )

Universitas Padjadjaran

Dewi Marhaeni Diah Herawati

Universitas Padjadjaran

Adiatma YM Siregar

Universitas Padjadjaran

Research article

Keywords: compliance, independent participants, premium, social health insurance

Posted Date: May 18th, 2020

DOI: https://doi.org/10.21203/rs.3.rs-26637/v1

License: (1) (i) This work is licensed under a Creative Commons Attribution 4.0 International License.

Read Full License 


\title{
Factors affecting independent participants of Indonesia's National Health Insurance in paying premium compliance: a qualitative study
}

\author{
Deni Kurniadi Sunjaya ${ }^{1}$, Dewi Marhaeni Diah Herawati ${ }^{2}$, Adiatma YM Siregar ${ }^{3}$
}

\section{Author List:}

${ }^{1}$ Departement of Public Health, Faculty of Medicine, Universitas Padjadjaran, Bandung 40161, West Java, Indonesia. dk_sunjaya@yahoo.co.id

${ }^{2}$ Departement of Public Health, Faculty of Medicine, Universitas Padjadjaran, Bandung 40161, West Java, Indonesia. dewimdh@yahoo.com

${ }^{3}$ Center for Economics and Development Studies, Departement of Economics, Faculty of Economics and Business, Universitas Padjadjaran,

Bandung 40115, West Java, Indonesia. adiatma.siregar@unpad.ac.id

*Corresponding author:

Deni K Sunjaya, Departement of Public Health, Faculty of Medicine, Universitas Padjadjaran, Jalan Eyckman No 38, Bandung, West Java, Indonesia dk_sunjaya@yahoo.co.id

Running Title: factors affecting payment contribution

\section{ORCID:}

Deni Kurniadi Sunjaya https://orcid.org/0000-0001-5781-0563 


\begin{abstract}
:
Background: There are currently 14\% independent participants in Indonesia's National Health Insurance (INHI) from the overall (199 million) participants. However, around $43.8 \%$ of them do not comply in paying the insurance premium. The purpose of the study is to explore factors that influence delinquent payment of contributions.

Methods: The research design was qualitative study with phenomenology approach and constructivism paradigm. Data collected by indepth interview and using theoretical sampling approach. We recruited 16 respondents of unpaid worker participants who arrear and who obey to pay the premiums from 4 difference cities/ districts. Triangulation was done trough 15 respondents from various stakeholders. We constructed substantive theory from data trough coding, cathegorizing and pattern matching.

Results: Compliance of paying insurance premium is affected by the intention to pay for contribution. Meanwhile, the intention to pay is influenced by the understanding of INHI program, financial ability, self attitude, operational system and service quality. These constructs consist of 5 to 8 indicators. To improve payment contribution of independent participants, INHI program has to pay attention for factors originating internally from the participants themselves and also externally: social and institutional environment support and the quality of health care and financing system.

Conclusions: INHI program need to improve a proper socialization, mechanisms for collecting beneficiary contributions, and strengthening the healthcare system, both for services and the implementation of the financing system.
\end{abstract}

Keywords: compliance, independent participants, premium, social health insurance 


\section{Background}

Since 2014 Indonesia has reformed the health financing system through Indonesia National Health Insurance (INHI) policy or what is known as Jaminan Kesehatan Nasional (JKN). INHI is a compulsory and centralyzed social health insurance with one operator for the whole country. According to Saksena, et al., health insurance is an important strategy for the protection of household finances [1]. Health insurance can increase the utilization of health services by the community. Health insurance also protects the poor from high care costs and provides financial security, reduces out of pocket financial expenditures, and promotes the use of drugs that are more cost effective $[2,3]$.

JKN management in the health sector is carried out by an agency called Social Security Administrative Body for Health (BPJS Kesehatan). After 4 years of implementation, the number of INHI participants reached 80\% (199 million) of the total population of Indonesia. The participants are classified into two types: premium assistance beneficiaries and non premium assistance beneficiaries including paid workers, unpaid workers, and non workers. Unpaid workers, which are independent participants, are around 14 percent of the total participants, but $43.84 \%$ of them fail to pay the premium regularly each month. This is one of the causes of the deficit problem face by JKN/ INHI program.

The reasons for participants being in arrears in paying contributions varried significantly. According to Mukangendo, et al., the main cause of Community-Based Health Insurance (CBHI) participants' being disobedient in paying premiums in Rwanda is due to economic incapacity [4]. The other causes are long waiting times in health services and premiums that are not affordable to the public. This opinion is reinforced by Mebratie, et al., who stated that the disobedience of participants in paying premiums in Ethiopia was due to the economic inability of the community [5]. Worknah, et al., shows that participants' age, affordability of premium costs, willingness to renew membership as members, occupation, attitudes and 
knowledge are predictors in the compliance of CBHI participants in Ethiopia [6]. Participant compliance will increase if the services needed by participants are sufficiently complete, infrastructure for health services are adequate, and medicines are complete with the requirements of professional health workers are needed.

This research initially used the Ability, Opportunity and Motivation (AOM) theory [7] as theoretical proposition. The indicators of the ability variables include sex of the household head, age of participants, number of household members, knowledge, social support, role of decision maker, ability to bear costs, and willingness to pay. Indicators in opportunity variables include access, payment attributes, roles to service places, and distance and travel time to the place of payment. Indicators in motivation variables include attitudes and beliefs, emotional/physical/social impulses, social norms, other priorities, intentions, and ability to pay and work.

The AOM or AMO (Ability, Motivation, Opportunity) theory was first introduced by Olander and Thögersen (1995), widely used in the fields of organizational behavior and psychology. The AMO framework is used as a basic concept of psychology that says that motivation is considered an incentive for behavior, and ability is an important skill to see behavior. While opportunity is a contextual and situational constraint that is relevant to a behavior [8]. Motivation is a complex concept, where the level and type of motivation are important aspects for someone to consider something [9]. Intrinsic motivation is defined as inherent behaviour in a person. Intrinsic motivation occurs because there is an urge to act from within a person, and they enjoy the behavior because there are challenges to complete tasks [10]. Extrinsic motivation is defined as a type of motivation that is controlled by externalities that are not part of a person's activity or behavior [9]. Ability consists of individual knowledge and skills. A person may have the intention or motivation to behave according to social rules, but behavior will not occur if a person's abilities are inadequate. Inadequate knowledge and 
skills will be barriers for someone to change their behavior [11]. Opportunities can improve compliance by increasing motivation and ability [12].

Compliance in paying contributions is very important for the sustainability of the social health insurance system. The implementation of the National Health Insurance, which has only been running for 4 years and experiences deficit, needs to be supported by an in-depth understanding of the incomplete payment of the contribution. The purpose of this study is to explore the factors that affect independent JKN participants in compliance with paying the premiums. Compliance with paying contributions is very important in the sustainability of the social health insurance system.

\section{Methods}

Study Design

The design of this study was qualitative study with phenomenological approaches and constructivism paradigms to produce substantive theories. This research is in accordance with the Declaration of Helsinki and has obtained ethical clearance from the Ethics Committee of the Faculty of Medicine inauthor's institution No. 780/UN6.KEP/EC/2018.

\section{Study Context}

Indonesia consists of more than 17 thousand islands with 8 large islands. Java as one of the largest islands is inhabited by $80 \%$ of the population. West Java is the province with the largest population (46 million in 2018). This province is divided into 27 districts/cities. The largest ethnic groups are Sundanese, followed by Javanese and various other ethnic groups. Most of the population has middle school level education. Illiteration still exists in 604,378 of the population. Indonesia as a democratic country has adopted a decentralized system since 2000 . Health services are provided by the Government and the private sectors. For public health 
services, there are hospitals belonging to the central and regional governments and Public Health Centers (Puskesmas) as primary health services.

\section{Subject}

The study population is unpaid worker participants who arrear to pay the premiums and who obey to pay the premiums. We collected the list of subjects from BPJS offices in its cities/ regencies. We did random sampling and go to the selected subjects at his/ her places.

The number of main subjects that were successfully recruited were 16 respondents (theoretical sampling) until there was saturation. For triangulation, we recruited 15 respondents from: BPJSKesehatan, the Social Service office, the Health Service Office and farmers, fishermen, and trader's associations. Unpaid worker respondents came from Cirebon City, Sukabumi City, Pangandaran District, and Garut District of West Java Province. Respondents of stakeholders for BPJS and the Health Service and Social Service were taken from cities/ regencies as well. Fishermen associations were from Pangandaran District, farmer associations were from Garut District, and merchant associations were from Cirebon City. The selection of cities and respondents for triangulation was done purposively. Therefore, the overall sample was 31 people.

\section{Data collection}

Data collection was carried out by in-depth interviews. Guidance for interview refers to the AMO theoretical proposition which are Ability, Motivation, Opportunity (Devine, 2009). We explored this construct and its indicators as mention in the background above. Interview done by researchers was directly analyzed before move to other respondents. So we convinced to produce a saturated codes and cathegories from these respondents. 
Triangulation methods was used to ensure trustworthiness. We interviewed stakeholders link to the result of main respondent perceptions.

\section{Analysis}

All the results of the interviews were first transcribed, followed by reduction, coding, cathegorization, theme development, pattern matching, concept mapping and theory development. Completing the concept map, we built the analysis in the form of thick description without including the quotations. We guarantee trustworthiness both in data collection and data analysis. To maintain credibility, methods and sources are triangulated. Peer debriefing was carried out together with the research team.

\section{Results}

Data analysis produced 101 codes, 34 subcategories, and 7 categories. Henceforth, we made the sub categories as a concept while the categories as constructs. Pattern matching construct a concept mapping visible in Figure 1.

The substantive theories that we have found are as follows: the compliance in contribution payment is influence by the Intention to Pay, Understanding of JKN (INHI), Financial capacity, Self-Attitude, Operationalization of insurance System and Quality of Services both from health care services and BPJS Offices.

Aspect of Understanding JKN consists of 6 concepts, which are: Dissemination of Information, Socialization, Self Awareness, Risk Understanding, Understanding of Utility, and Understanding of Packages' Benefits. Financial Capacity aspect consist of 6 concepts, namely: Membership Class, Ability to Pay Contribution, Ability to Bear Cost, Continuity of Payment, Income Regularity, and Priority Choice. The Self-Attitude aspect consist of 8 concepts, namely: Personal Belief, Family and Society Encouragement, Social Norms, Social Traits, 
Motivation of Participation, Treatment Experience, Perception of Loss, and Perception of Health Care Services. The Operational System aspect has 8 concepts, namely: Access, Penalty, Regulation, Portability, Other Financing Alternatives, Local Government Involvement, Procedures Complexity in Healthcare Facilities and The Role and Function JKN Cadres. Lastly, the aspect of Service Quality consists of: Waiting Time, Discrimination, Brokering in Hospitals, Administrative Complexity and Availability of BPJS-Kesehatan Offices.

Theme 1: Understanding of INHI

\section{Dissemination of Information}

According to the participants, the dissemination of information on JKN program from the district government is low. However, for people who have a good level of education and financially capable, dissemination information is obtained through television media so that many capable participants who participate in private insurance decide to switch to JKN (unpaid worker) participants. Some participants understood that the JKN premium was paid by the government, which led to the assumption that $\mathrm{JKN}$ is free.

\section{Socialization}

One respondent suggested that socialization should be carried out routinely until the community understands about $\mathrm{JKN}$ so that they could convince the community to participate as JKN participants and is willing to pay contributions regularly. The form of socialization can be done by meeting and discussing with community groups continuously. In dissemining the program, it is necessary to emphasize cross subsidies where the rich are asked to help the poor, and the healthy ones help the sick. Socialization should be able to change the way people think, that the healthy ones help the sick. If people suffer from illness, the community is also helped by other healthy communities. Therefore, socialization is not only done once in certain groups because it does not reach the lower levels. 


\section{Self Awareness}

Public awareness to become BPJS Kesehatan participants is still low. The condition of "prevention is better than cure" has not been formed. Often people just make or manage the membership cards and pay contributions when they get sick. The way people think about the need for INHI participation is when they are getting sick. Therefore, the community considers that it is not important to pay the contributions. This is because the community has not received clear information about the program, causing self-awareness to pay dues to be low. However, some people already have self-awareness to obey paying contributions.

\section{Risk Understanding}

The majority of participants understand the risks if they arrear in paying premium fees. However, because they do not have money, participants cannot afford to pay the contributions. The participants do not feel loss when they don't file a claim because they understand that they have helped other participants when exposed to the risk of illness. Participants are very confident that JKN become an aid when exposed to the risk of illness even though in reality participants and families rarely get sick the past 4 years.

\section{Understanding of the Utility}

Some participants understand the use of JKN, which is to guard against illness so that the payment will not be tough. The use of JKN is to alleviate health costs when a person is getting sick. In fact, the majority of the participating communities have already understood the use of JKN. Participants understand that the $\mathrm{JKN}$ program is a mutual cooperation program. JKN is a solution that fits the needs and abilities of participants in fulfilling the protection of the health of themselves and their families. 


\section{Understanding of Package Benefits}

Most participants of unpaid worker haven't understood about the advantages of JKN. The JKN program is actually a preventive promotive program, a healthy community movement. The preventive program means that healthy people must be managed well, and this is what has been promoted. The $\mathrm{JKN}$ program is a program to prevent sick people and people in general from going bankrupt when get sick because of expensive service costs.

The majority of participants do not understand that JKN is a health insurance which affect their way of thinking. They see JKN not as a health insurance, but rather as something needed only when get sick; thus, when they are not get sick, they will not pay for the contributions. According to participants, the benefits received are far greater than the costs they have to pay each month. The existence of JKN which implements a cheap monthly fee system, provides an alternative for them get affordable health services.

\section{Theme 2: Financial Ability}

\section{Ability to Pay the Contributions}

The compliance in paying premiums in low income communities are generally low. Some participants should be included in the premium assistance beneficiary, but they are not registered as poor people so they enter as unpaid worker participants, and they cannot afford to pay the premiums but must pay it. When viewed from the socio-economic side of the community, there are several groups of people who have irregular income. This worsens the condition of why unpaid worker participants are in arrears. For unpaid worker participants whose income is not fixed, paying Class 3 contributions of Rp. 25,500 per month is considered quite tough. 
A participant suggested that the government should do an initial screening about the income of the community so that they only have to be grouped as premium assistance beneficiaries, unpaid workers, paid workers, etc. The initial screening for community income will reduce the number of participants that is incapable to pay or poor in the unpaid workers. In addition to initial screening about income, it is also necessary to screen household finance expenditures. This is important to be done so that it can be known whether the community is truly incapable, or because it is unable to allocate household financial expenses properly. Assesing whether household financial expenditures is widely used to finance secondary needs compared to primary needs.

\section{Ability to Bear Costs}

Reluctance to pay contributions is also related to the number of family members that must be borne by the head of a family. Although the contribution value per person is not considered burdensome, the large number of family members causes the total contribution to be paid to be large. This is a significant burden for the head of a family. Payment of contributions that must be routinely carried out every month is considered not commensurate compared to paying for incidental health services. The community feels that if a person does not get sick too often, there is no need for a routine expenditure. In addition, they feel the cost of accessing health services is still affordable.

\section{Continuity of Payment}

Non-routine cost payment does not only occur in disadvantaged groups but also in capable groups. In the incapable community groups, the cause of non-regular payment is due to the insufficient money they have while in the capable group, is lack of motivation and time due to busyness in their job which then cause them to forget to pay the contributions. 
Contribution payment from participants who receive irregular income, such as traders, fishermen, etc., in general, become hampered. This is because their income is not constant and not routine. However, most unpaid worker participants always pay regularly because if they do not pay regularly, the fee will be fined and if it is not paid directly, the penalty will be quite large.

\section{Income Regularity}

In general, income of farmers and the traders is small and often irregular, creating difficulties for the participants pay premiums. Irregularity problems are also complained of by participants who have just lost their jobs that they can not pay premiums. The main thing is that participants must still pay premium contributions. However, some participants later receive loans from their families (e.g. parents and in-laws and relatives) to pay JKN contributions.

\section{Priority Choices}

Most people prioritize secondary needs apart from JKN premium payments. More than that, people think rather than paying $\mathrm{JKN}$ premiums every month, it is better if the money is used to buy other things such as buying temporary motorbikes in installments. Meanwhile, the main priority for fishermen is food and equipment for fishing such as nets. Fishing equipment cause a big expense for the fishermen because the condition of the equipment cannot be predicted, and the price is quite expensive. This has caused the fishing community to be less concerned about JKN.

Other participants said that they are in arrears in paying contributions because there are other priorities that have to be fulfilled beforehand such as financing children who enter junior and senior high school, paying rent etc. However, they do have the intention to pay if they have enough money. 
It seems that this other priority is also a variable that causes participants not to pay dues, more for participants whose income is mediocre. However, for participants who are capable in paying, priority will not be an obstacle to not paying JKN contributions.

\section{Membership Class}

The majority of the participants, including participants who are well-off, choose to become JKN Class 3 participants. If they need to be admitted to the hospital, they would ask to upgrade to Class 1 by paying a shortage of money. This happens because the premium fee for Class 1 is quite expensive if their income decreaseds. Therefore, the participants choose to become the Class 3 members.

Theme 3: Self-Attitude

Personal Beliefs

Another factor that influences the reluctance to pay contributions is the values or beliefs adopted by JKN participants. One respondent said that he is reluctant to pay the contributions because the JKN system or the insurance system contradicts with his beliefs. Belief which is held by the respondents is to encourage more submission to the Almighty when experiencing pain. He also believed that any health care system will not be able to overcome the Almighty's destiny. For cases like this, it is better if JKN provides an alternative coverage system that is adjusted to such beliefs or religions.

For the belief issue, it seems that it is more because of the communication by BPJS Kesehatan and the local government has not been carried out continuously so that some people still misinterpret it. Therefore, good communication promoting JKN is a very important thing to do, especially by cooperating with religious leaders or religious teachers to approach groups of people whose confidence about the JKN program is still lacking. 


\section{Family and Society Encouragement}

According to some participants, mostly, the decision-making to become JKN participants and willingness to pay regularly very much depends on the decision of the head of the family. In addition, the role of the parents is very significant, both in pushing to become JKN participants and when paying the premium fees. If the participants forget to pay the premiums on time or because there are other things to be paid then the parents would pay their contributions.

\section{Social Norms}

Some people have a norm that the JKN program is usury, but after the regulations have been changed, many people now understand that the JKN program is not usury. The community is aware that it is usury if there is a fine in the payment of premiums. The participants who are overdue for more than 6 months are subjects to a $2 \%$ fine, which is called usury. Based on Presidential Regulation (Perpres) No. 28 of 2016, the fines are eliminated and converted into service fines.

\section{Social Traits}

According to one respondent, he always pays the contributions because he wants to help others. Although it is felt that he actually feels that paying the premiums during their lifetime is a burden, if they think about the reward which is abundant from Allah SWT, the respondents would choose to get the reward from "The Above" in order to help others who need it. For participants whose social traits are good, they have a principle that if they still have money, it is better to help others in need. 


\section{Motivation for Participation}

The respondents from a well-off community have a strong motivation for the participation because previously, many participated in private insurances, such as Prudentia. However, for the poor community, the motivation to participate is because they or their families suffer from a severe illness and/or require some services at the hospital. In general, the motivation of the community as participants is due to necessity, when one of the family members is sick.

\section{Treatment Experience}

The respondents think that they had some unpleasant experiences in medical care at the hospitals and healthcare centers. However, there are still some participants who said that the service in the hospital currently is quite good and has undergone improvements. It also happens to the services at the Puskesmas because currently there is an accreditation which makes the Puskesmas and hospitals required to provide better and standardized services.

The things that are most problematic in healthcare services are the long queues and poor hospitality of the healthcare personnels. According to some respondents, other services that are less optimal are the availability of rooms for JKN card holder's patients. Even though hospital services have not been maximized, they consider the services provided are still acceptable, if only the medicines for JKN participants are not being reduced.

\section{Perception of Healthcare Services}

All of the respondents said that the perception of healthcare services are progressive and have improvements. This happens because of the impact of accreditation for the Puskesmas and hospitals. It was different from the previous years, when the Puskesmas and hospital services were one of the reasons for the participants' uncompliance in paying the premiums. However, there are still a number of Puskesmas and hospitals whose healthcare personnels are not 
friendly towards $\mathrm{JKN}$ participants, especially the personnels in the registration or administration section. According to the respondents, the majority of services by doctors at the Puskesmas and hospitals are good and friendly towards the patients, and they do not discriminate JKN and non-JKN card holder's patients.

\section{Perception of Loss}

Some respondents from the well-off socio-economic group are able to say that they incur losses if they pay for the JKN contributions. They assume that they would pay contributions only when they are sick, and if they are not sick, the money should be returned to the participants. This shows that the participants do not understand the concept of a healthcare insurance. Other respondents said that the environment around their residence has a perception that the JKN are detrimental because if they are not sick, the collected contributions would be forfeited, unlike the the BPJS Ketengakerjaan insurance whose funds could be disbursed when retired. Another perception from the participants' neighbours is that the accumulation of the contributions collected are greater than the costs when they are sick, so $\mathrm{JKN}$ in their point of view is detrimental.

Theme 4: System

Access

According to some of the respondents, access to premium payments is now easier because people can pay directly to BPJS or through several banks that collaborate with BPJS, such as BRI (a government owned bank). They can also pay via Alfamart and Indomaret (supermarket frenchises). However, there are respondents who said that not everyone has an easy access to pay JKN. For example, In the Bungbulang sub-district, there are 13 villages of which 9 villages are located in geographically difficult areas. To be able to reach the sub-district, they need 
transportation which costs around Rp100,000. In addition, the access to pay JKN contributions using BRI-links is often constrained by poor internet signals.

According to one of the respondents, participants would like to have an access to a flexible payment system in the sense of not having to pay premiums every month. This is because it would be easier for the participants who do not have regular basis wages. With daily or weekly installments systems, it probably could make the access to pay the JKN contributions easier for the participants.

\section{Penalty}

Currently, the penalty for those who fail to pay the premiums for more than 13 months is that they must pay a 12-month contribution plus an extra of one month when they are sick before 4 months of active payment then get a fine at the hospital of $2.5 \%$ of the service fee. The maximum fine in the service is Rp30,000,000, and the fine may not exceed the maximum limit.

There are respondents who disagree with the penalty applied by JKN for those who fail to pay the fees. It is better if the obligation is covered by the government, especially for the poor people. The national obligation is to care for its people, so the participants do not agree if the people who fail to pay would get a penalty.

The respondents suggested that the participants who have had used JKN services should get penalty when they do not comply with the payments. However, the participants who have never used JKN services should not get a penalty. Other respondents wished that the participants who are delayed in paying a one-month premium should not be fined. It is recommended that penalty should only be given to participants who have the intention of not paying the contributions while for the participants who have problems with their finances, they should not get a penalty. 


\section{Regulation}

Several municipal districts in West Java Province currently have 3 free programs regulations, which are free rice for the poor, free education from elementary school to high school, as well as free healthcare services. This causes the community's compliance in paying the JKN contributions become low because they think that everything is free. Free health care programs are only in the primary care, but if you need a secondary healthcare services, not every disease is free. There are several diseases of which the patients are asked to do cost sharing.

The Central Government has made regulations in JKN-KIS, but it seems that it cannot be done consistently. It is proven that some patients are well off and even own cars but are registered as Penerima Bantuan Iuran (PBI) or Contribution Assistance Beneficiaries, whose premium is paid by the government.

\section{Portability}

All respondents wished that the JKN participants should get healthcare services throughout Indonesia. When participants are out of town and experience to get sick, the JKN could be used anywhere. The experience of one respondent when she was going to another city shows that the JKN card could not be used. This makes the participants disappointed. The existence of these problems causes participants to be disappointed with the BPJS Kesehatan service and become noncompliant in paying the contributions.

\section{Other Financing Alternatives}

Some respondents stated that there should be other alternatives in financing the contributions. For people who regularly pay the premiums but from the poor family, the solution offered is to rely on other sources such as CSR and Zakat so that they could do cost sharing with the participants. Whereas, for people who are well off but do not want to pay the premium fees, 
there is a new scheme above Class 1 so that they could withdraw money from the community who could afford to prioritize service quality.

\section{Local Government Involvement}

The local governments in some villages have been involved in providing dissemination of information about the importance of JKN to the community. Besides that, these governments are also involved in billing participants who arrear because many of them who are billed are from villages. At the beginning of the JKN program, the villages also facilitated participants to pay contributions, but after that, they have to pay the contributions by themselves.

According to one of the heads of village interviewed, the payment should only be collected by the village so that they could help monitor who have not become a JKN participant and who arrears. According to him, payments through the village office would be more efficient, the distance is closer, and it is easier to communicate with villagers if there is a delay in paying JKN contributions. This is reinforced by resource persons from the Dinas Kesehatan (Health Office), where the Village Government and Puskesmas should be involved both in conducting information dissemination, communicating about JKN and BPJS. The Village Government is also involved in the data collection of the participants and the participants who arrear. This is important so that the Village Government can remind their citizens to pay contributions in a timely manner.

\section{Procedures Complexity in Healthcare Facilities}

Some of the JKN participants who sometimes do not bring their JKN card when they are get sick and need care at the Puskesmas, prefer to pay directly. According to the respondents, they feel that the administrative procedure is complicated, especially if they need a referral of very complicated illnesses. When the participants need an outpatient care, mostly choose to pay 
directly. However, if they need to be admitted to the inpatient care, new participants usually use their JKN card.

\section{The Role and Function of JKN Cadres}

There are three roles of cadres according to the respondents, namely helping the community in the registration to become JKN participants, collecting contributions, and reminding the participants if it is time to pay the contributions. In addition, they accommodate the participants' complaints and helps to find solutions. The other role of cadres is sometimes to bail out the participants' contributions, if they fail to pay it on time. The cadres do this because they feel sorry for the participants.

According to one respondent, the cadres must be qualified. Therefore, the cadre's abilities must be increased through training so that they increase not only their knowledge but also their skills in motivating JKN participants. The cadres may provide information and education to the community at the recitation place, in people's homes, in stalls, etc.

According to other respondents, the role of cadres is to assist participants when they need treatment at the hospital. They could also act as facilitators of JKN participants. Respondents also want BPJS Kesehatan to improve the role of cadres by making them the spearhead of the service. This could have an impact on improving BPJS Kesehatan services, especially in terms of services that have been carried out by the office. Therefore, it is expected that BPJS Kesehatan could improve their services by upgrading the roles of cadres.

Theme 5: Service Quality

\section{Waiting Time}

The waiting time for registration in one of the public hospitals is around 2 hours long, so is the waiting time when collecting the medicines. This happens because patients in the hospital are 
very numerous. There are only two registration counters maximum in the hospital. Some respondents even said that they had the experience coming to the hospital at 9 AM and finally met the doctors at 4 PM. The same thing goes when collecting the medicine in the pharmacy where the officers have become lazy to serve because it is the end of their working shift and the replacement officers usually have not arrived.

Another respondent said that the queue in Puskesmas registration section if using a JKN card is very long. The participants prefer to pay for themselves because they only have to pay for Rp5,000, but the service is faster than using JKN card. The waiting time for doctor consultation is also quite long, which is around 30-40 minutes. If the patient's condition is serious, waiting for 30-40 minutes is a torture for them. However, if the patient is only mildly ill, this waiting time is still bearable.

This long waiting period at the registration section, doctor's consultation, as well as in the pharmacy cause the patients waste a lot of their time. In addition to worsen the pain, they even lose time to earn income. All respondents want the Puskesmas and hospitals to improve the system to make the waiting time shorter.

\section{Discrimination}

One participant expressed a presence of discrimination in healthcare facilities. This is also recognized by several other respondents when they were at the puskesmas or hospital, they were being discriminated. JKN participants are separated from general patients when collecting the medicines. They are ruled out both in service and collecting medicines. In addition, the medicine given is only half a package, the rest is said to buy somewhere else by themselves. The reason for what the hospital pharmacy officers have done is because of the limited availability of the drugs. According to some respondents, people who use JKN card are often asked to buy the drugs outside the hospital pharmacy. Although the price is not expensive, it 
irritates the JKN participants. Patients feel distinguished from the general patients whose medicines are provided at the hospital. Pharmacies for general patients and JKN patients, in fact, are indeed distinguished.

\section{Brokering in the Hospital}

Most of the respondents complained about the broker in the hospital. Cases of the brokering in the hospitals, based on the respondents' observations, have happened for a long time. Brokers could come from hospital personnels themselves or other community members who have professions as brokers. The community when admitted to the hospital prefer to be managed by brokers rather than taking care of their own administrative procedure. If participants take care of it by themselves, the hospital administration often say that the hospital room is full then they are only placed in the hospital hallway. Meanwhile, if the respondents use the brokers, they could get a room for hospitalization. The brokers fee ranges from Rp1000,000 - Rp2,000,000. This is another problem for the respondents because they have to borrow money from friends or relatives first. However, according to the respondents, it is more difficult to manage it by themselves, so they prefer doing transaction through brokers because they do not have to fight and get pissed off by the hospital personnels.

\section{Administration Complexity in the BPJS Kesehatan Office}

The complexity in the administration problem is complained by almost all respondents. Often the data between their JKN card and ID card is not the same, and the administration process to correct this in the BPJS Kesehatan office could take two days long even though it is only one letter correction. As a result, participants cannot go to the Puskesmas, especially to ask for referral letters. The difficulty in administration process at BPJS-K office had become well known in community. Therefore, people prefer to seek medical treatment as general patients 
rather than JKN, and especially for those who are well off, they choose not to become JKN participants.

\section{Availability of the BPJS Kesehatan Offices}

The imbalance between the number of branch offices with the number of JKN participants makes the service to participants not optimal. The poor quality of service in the BPJS Kesehatan offices is complained by some respondents in this study.

\section{Intention to Pay for the Contributions}

The majority of respondents who are in arrears said if they have enough money, they would have the intention to pay the JKN contributions. In fact, there are respondents who actually do not have any income and want to keep paying the contributions. However, some participants do not have the intention to pay. This is due to many things such as mistaken beliefs and perceptions of the JKN program, unpleasant experiences in healthcare facilities, lack of money, having other priorities, and some of which are caused by consumptive lifestyle so that they cannot pay the contributions on schedule.

Some respondents want to pay their arrears easily, such as weekly or daily installment. The respondents said that even though they do not pay the contributions, they actually always remember that they have to pay the JKN contributions. However, because the respondents have some personal problems as stated above, they are bound not to pay the contributions.

\section{Discussion}

The substantive theory found in this theory is very different from the initial theory used, which was the AOM framework from the World Bank [7]. In this study, it is explained that someone's compliance is influenced by one's intention in paying the contributions. This finding is similar 
to the findings of Lin, et al., study who state that the intention strongly predicts the medication compliance among patients who undergo coronary artery bypass graft (CABG) [13]. The results of this study are also supported by the study from Fai, et al., which show that attitudes and intentions are positively related in improving compliance of taking oral antihyperglycemic regimens [14].

The results of this study also show that the intention to pay contributions was influenced by the five constructs, including understanding of the JKN program, financial ability, self-attitude, system, and service quality. According to Aprianti, et al., factors which are related to someone's intention to consume iron tablets in young women are perceived threats, perceived benefits, perceived barriers and perceived self-efficacy [15].

The results of this study show that the construct of understanding about the JKN program is influenced by information dissemination, promotion, self-awareness, understanding of risks, use, and benefit packages. These results are supported by Buzatu, which reports that someone is interested in buying insurance because they understand the information about the importance of having an insurance [16]. The results of this study are also in accordance to the research by Obse, et al., who conclude that the understanding and knowledge of a low benefit health insurance package in Addis Ababa is led to low participation and willingness to pay [17]. Buzatu study also states that the perception of high health risk is significantly related to participation and willingness to have a health insurance [16]. Compliance participant can be improved through the provision of information, such as education or dissemination information [18]. According to Buzatu, someone is willing to pay for insurance if they are afraid of particular events, such as car theft or house damage caused by a natural disaster [16].

This study also shows that the construct of financial ability is influenced by the ability to pay, the ability to bear costs, the continuity of payment, regular income, the existence of other priorities, and the health insurance class. This result is supported by Buzatu who reports that 
the reason why someone refuses to buy insurance is the perception associated with the future income constraints and lack of available funds [16]. This result is also in accordance with the study conducted by Adebayo, et al., who show that low income rate and lack of financial resources are the main causes for someone to become a health insurance participant (CBHI) [19].

One of the results of this study is that the construct of self-attitude is influenced by personal beliefs, family/social encouragement, social norms, social characteristics, participation motives, medical experience, perception of losses, and perceptions of healthcare services. This is supported by Buzatu study results which state that someone who is willing to pay the premium contributions and wants to take part in an insurance because it is influenced by social norms [16]. Social norms are informal rules which are followed by all members of the community. These norms would be followed by all members of the community, but there is no punishment for those who do not obey them, but family, close friends, and the community would reject them. Life insurance in the United States in 1978 was rejected by the community because it was considered as a desecration which changed the sacred event of death. The results of this study show that there is a group of people who consider that the JKN program is usury because there are penalties.

The study results show that the construct of the system is influenced by access, penalty, regulations, other financing alternatives, local government involvement, the complexity of procedures, and the role of JKN cadres. This results are in accordance with the meta-analysis conducted by Dror, et al., which show that the factors which prevent someone from becoming a CBHI participant are due to access, inadequate policies regarding $\mathrm{CBHI}$, and benefit of the packages that are not what the participants desire [20]. The results of this study are also supported by Donfout, et al., which state that the government involvement is very important, especially in conducting campaigns and social marketing related to the importance of becoming 
CBHI participants [21]. Community involvement in NHIS activities is key to promoting participant interest and compliance [22].

This study shows that the construct of service quality is influenced by waiting times, discrimination, brokering in the hospitals, administrative complexity, length of the queue and the number of BPJS Kesehatan branch offices. These results are in accordance with the research conducted by Adebayo, et al., Uthman, Wiysonge, Stern, Lamont \& Ataguba (2015) which state that the poor quality of healthcare services, including the availability of drugs and medical equipment, poor attitudes of the healthcare personnels, and long waiting times cause people not participating in a health insurance (CBHI) [19]. Trust in the CBHI scheme and healthcare providers also affect the desire of the community to join the CBHI. Compliance of participants is influenced by satisfaction health services [23]. Compliance of participant is also influences by the avalibility of health services needed by the participants [24].

Social health insurance in Indonesia was regulated in 2004 (the end of the Megawati's administration), and then experienced a slowdown in the preparation of implementation in the next two periods of leadership of Susilo Bambang Yudhoyono. The new INHI could be implemented in the period of Joko Widodo (2014) with minimum preparations. It was also coupled with the ambitious universal health coverage target in 2019, which was related to insured all 250 million residents of Indonesia.

\section{Socialization}

In addition to the large amount, the reform of the financing system is related to changes in payment habits for healthcare services. The community has been using an out of pocket payment for decades. When you have to buy upfront, without sufficient socialization and enough time, there is a consequence that must be paid in the form of not paying this fee. Rather 
than targeting universal healthcare within 5 years, there should be certain activities in the dissemination of information related to the new financing system.

The insurance providers often convey about "socialization activities" but in reality it is only the dissemination of information. The dissemination should be recognized as understanding the risks and making the concept of mutual cooperation, as well as paying up-front contributions before get sick as daily behavior for their health insurance. Dissemination only increases knowledge, without being a regular behavior in the community life. Thus, it is necessary to develop more targeted and sustainable forms of socialization activities to change people's behavior. Good socialization could be performed to overcome the challenges of negative influences from the society and confirmation bias due to incorrect information.

Resetting the dynamics of premium-subsidized target groups

Inability to pay is also arised issue. The government has fulfilled their obligation to pay more than $100 \%$ of the premium for the people who are considered as poor, even far exceeds the actual poverty rate. It means that not only the poor, but also the middleclass people's premiums are partially paid by the government. It is evident that the cost of the government contributions for the population is unable to far exceed the utilization by the poor community, or the premium for the poor people also includes those who pay independently.

Economic capabilities are dynamic. It is possible for someone to be able to pay today, and not on the next day or vice versa. Therefore, it is necessary to identify the dynamic population of the poor. This is also related to the dynamic income system of the poor. The determination of the right on target for covering the premium for the poor also needs to be added within the system that could overcome the problem of inability to pay at any time or status change to become unable to pay independently. 
Strengthening the Health System

The disappointment towards the healthcare system and the financing system managed by BPJS Kesehatan has caused the patients or residents to stay away from the JKN financing system. Strengthening the healthcare system in term of the availability and quality of health services could lead to public trust in $\mathrm{JKN}$, likewise for the administrative services from $\mathrm{JKN}$ organization.

Limitation of this study is that it does not cover out of Java island context. It could be losing perception basedon ethnicity and custom. The substantive theory constructed will be followed by quantitative research for the needs of inference and generalization.

\section{Conclusions}

The independent participants of JKN's non-compliance with paying contributions is caused by factors originating from the internal of the participants themselves, namely understanding about JKN, self-attitudes, and financial ability; and from external of the participants, namely: social influences, quality of healthcare and financing systems. Improvements needed are proper socialization, mechanisms for collecting beneficiary contributions, and strengthening the healthcare system, both for services and the implementation of the financing system.

The independent JKN participants are a very important part of the social health insurance context. The sustainability of paying of the independent participants in JKN reduces the government's burden in overcoming deficit. It is also a true picture of social health insurance's success in Indonesia.

\section{Abbreviation}

INHI: Indonesia National Health Insurance; JKN: Jaminan Kesehatan Nasional; Social Security Administrative Body for Health (BPJS Kesehatan); CBHI: Community-Based Health 
Insurance; AOM: Ability, Opportunity and Motivation; AMO: Ability, Motivation and Opportunity; Public Helath Center: Puskesmas.

\section{Declaration}

Ethics approval and concent to participate

The study was approved by the Ethical Committee of Universitas Padjadjaran No. 780/UN6.KEP/EC/2018. Written informed consent was received from all participants before participating in this study.

\section{Consent for publications}

Not applicable.

\section{Availability of data and material}

The datasets used and/or analysed during the current study is available from the corresponding author on reasonable request.

\section{Competing Interests}

The authors declare that they have no competing interests.

\section{Funding}

The study was funded by BPJS Kesehatan for data collection and analysis. BPJS Kesehatan only have limited role in the conduct of the study and does not interfere with the objectivitiy of the study.

\section{Authors' Contributions}

DKS designed the study, analyzed the data and prepared the manuscript. DMDH and AYMS prepared the manuscript for publication. All authors contributed the writing and have read and approved the final manuscript. 


\section{Acknowledgments}

The authors would like to thank BPJS Kesehatan, Deputy Director of Research and Development and staffs; participants and all stakeholders for the supporting the data collection of this research.

\section{References}

1. Saksena P, Antunes AF, Xu K, Musango L, Carrin G. Mutual health insurance in Rwanda: evidence on access to care and financial risk protection. Health Policy. 2011; 99:203-9. doi: 10.1016/j.healthpol.2010.09.009.

2. Jacobs B, Bigdeli M, van Pelt M. Ir. P, Salze C, Criel B. Bridging community-based health insurance and social protection for health care-a step in the direction of universal coverage? Trop Med Int Health. 2008;13(2): 140-3.

3. Faden L, Vialle-Valentin C, Ross-Degnan D, Wagner A. Active pharmaceutical management strategies of health insurance systems to improve cost-effective use of medicines in low-and middle-income countries: a systematic review of current evidence. Health Policy. 2011;100: 134-43. doi: 10.1016/j.healthpol.2010.10.020.

4. Mukangendo M, Nzayirambaho M, Hitimna R, Yamuragiye A. Factors contributing to low adherence to community-based health insurance in Rural Nyanza District, Suthern Rwanda. Journal of Enviromental and Public Health. 2018. Article ID 2624591:9 https://doi.org/10.1155/2018/2624591.

5. Mebartie AD, Sparrow R, Yilma Z, Alemu G, Bedi AS. Dropping out of Ethiopia's community-baased health insurance. Health Policy and Planning. 2015;30(10):1296-306.

6. Workneh SG, Biks GA, Woreta SA. Community based health insurance and communities' scheme requirement compliance in Thehuldere district, northeast Ethiopia: cross sectional community-based study. Clinico Economics and Outcomes Research. 2017; 9: 353-9.

7. Devine J. Introducing sanifoam: A framework to analyze sanitation behaviors to design effective sanitation programs. Water Sanitation Program, World Bank. 2009.

8. Trost JK, Skerlajav M, Anzengruber J. Team innovation: efficacy beliefs, proactive personalities, supportive supervision and team innovation. Economic and Business Review. 2016;18(1): 77-102.

9. Petri HL, Govern JM. Motivation theory, research and applications (5th Ed.). Belmont CA: Wadsworth/Thompson Learning. 2004.

10. Ryan RM, Deci EL. Self-determination theory and the facilitation of intrinsic motivation, social development and well being. American Psychologist. 2000:55(1): 68-78.

11. McKenzie-Mohr D. Fostering sustainable behavior through community-based social marketing. American-Psychologist. 2000; 55(5); 531-37.

12. Taira DA, Wong KS, Frech-Tamas F, Chung RS. Copayment level and compliance with antihypertensive medication: analysis and policy implications for managed care. American Journal of Managed Care. 2006;12(11); 678-84.

13. Lin CY, Updegraff JA, Pakpour AH. The relationship between the theory of planned behavior and medication adherence in patients with epilepsy. Epilepsy \& Behavior, 2016;61: 231-6. 
14. Fai EK, Anderson C, Ferreros V. Role of attitudes and intentions in predicting to oral diabetes medications. Endocrine Connections. 2017;6(2): 63-70. doi: 10.1530/EC-160093.

15. Aprianti R, Sari G, Kusumaningrum T. Factors correlated with the intention of iron tablet consumption among female adolescent. Journal Ners. 2018;13(1):122-7.

16. Buzatu C. The influences of behavioral factors on insurance decision - a romanian approach. Procedia Economics and Finance. 2013;6:31-40.

17. Obse A, Hailemariam D, Normand C. Knowledge of and preferences for health insurances among formal sector employees in Addis Ababa: a qualitative study. BMC Health Services Research. 2015;15:318.

18. Iuga AO, McQuire MJ. Adherence and health costs. Risk Management and Health Care Policy. 2014;7:35-44. doi: 10.2147/RMHP.S19801.

19. Adebayo EF, Uthman OA, Wiysonge CS, Stern EA, Lamont KT, Ataguba JE. A systematic review of factors that affect uptake of community-based health insurance in low-income and middle-income countries. BMC Health Services Research. 2015;15: 543.

20. Dror DM, Hossain SAS, Majundar A, Koehlmoos TLP, John D, Panda PK. What factors affect voluntary uptake of community-based health insurance schemes in low-and middleincome countries? a systematic review and meta analysis. Plos One. 2016. doi: 10.1371/journal.poe.0160479.

21. Donfout HP, Makaudze E, Mahieu PA, Malin E. The determinants of the willingness-topay for community-based prepayment scheme in rural Cameroon. International Journal Health Care Finance Economic. 2011;11(3): 209-20. doi: 10.007/s10754-011-9097-3.

22. Alhassan RK, Spieker N, Nketiah-Amponsah E, Arhinful DK, Rinke de Wit TF. Assessing the impact of community engagement interventions on health worker motivation and experiences with clients in primary health facilities in Ghana: a randomized cluster trial. PLoS One. 2016:11(7): 1-19. doi: 10.1371/journal.pone.0158541.

23. Onwujekwe O, Onoka C, Uzochukwu B, Okoli C, Obikeze E, Eze S. Is community-based health insurance an equitable strategy for paying for healthcare? Experiences from southeast Nigeria. Health Policy. 2009; 92(1):96-102.

24. Oriakhi HO, Onemolease EA. Determinants of rural household's willingness to participate in community based health insurance scheme in Edo State, Nigeria. Ethno-Medicine. 2012;6(2):95-102. 


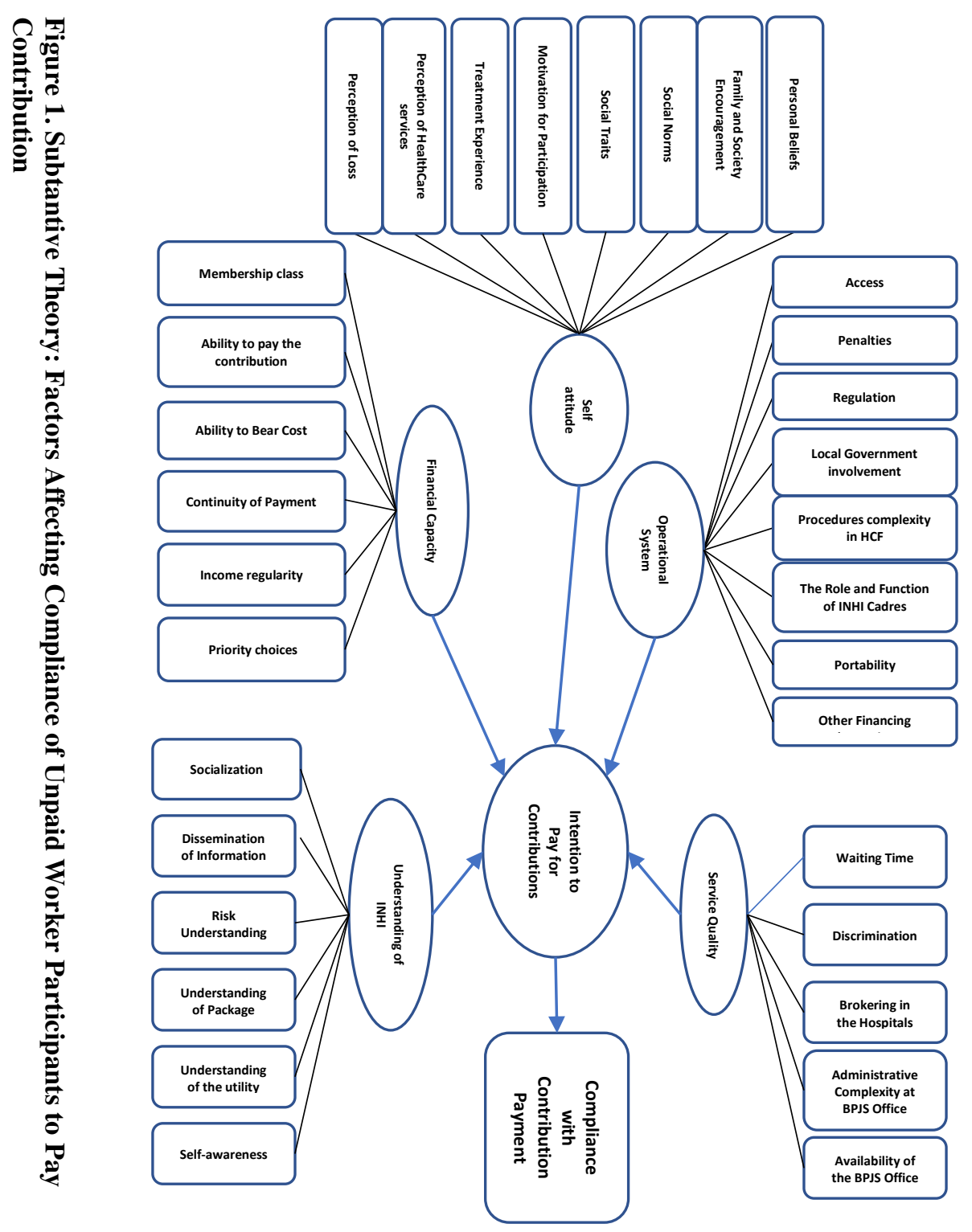


Figures

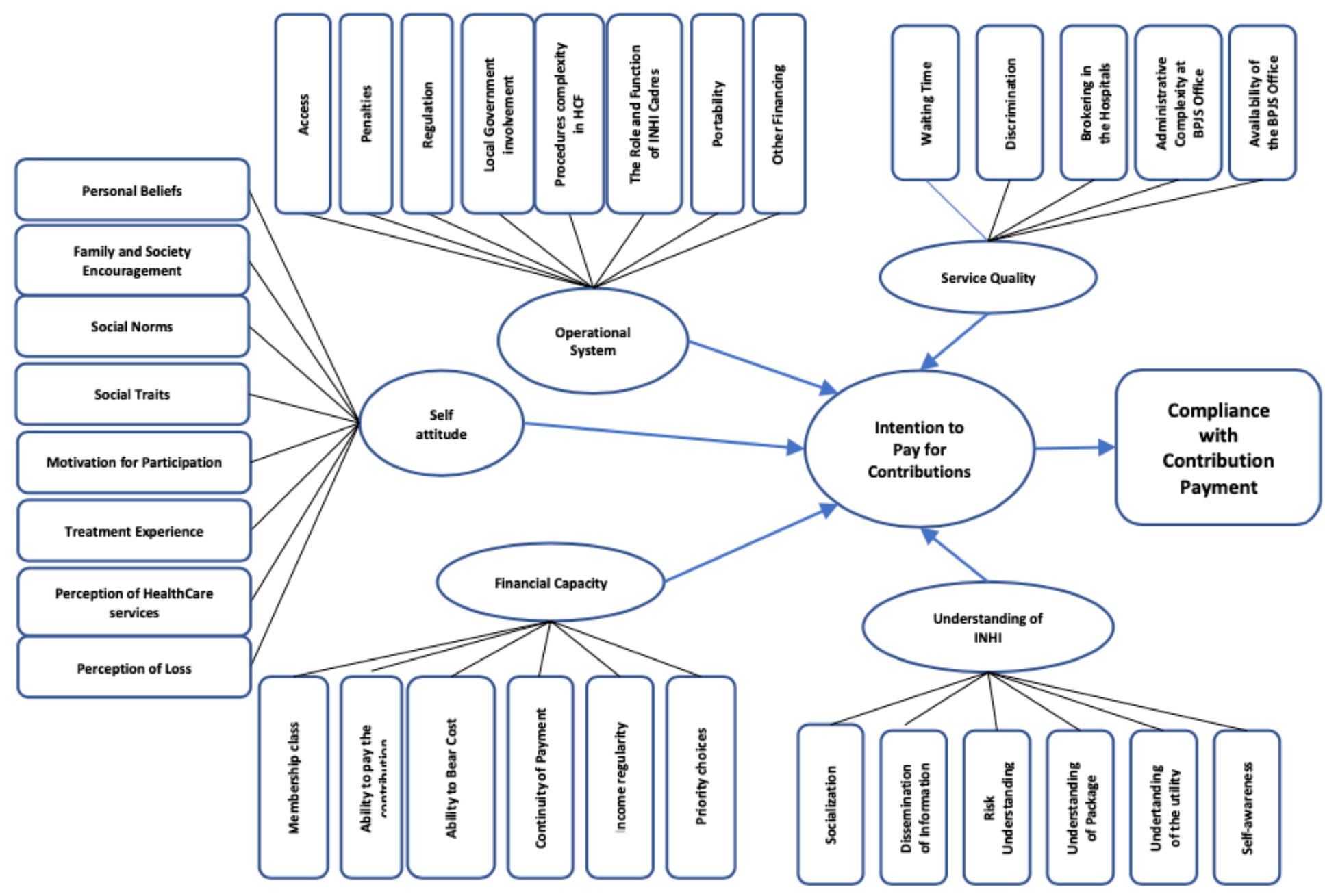

Figure 1 